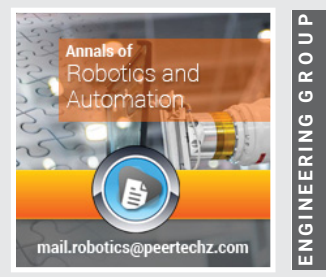

\section{The Future of Robots in a}

\section{Super-Aged Society}

\author{
Ala Szczepura ${ }^{1 *}$, Toshio Nomura ${ }^{1,2}$ and Deidre Wild ${ }^{1}$ \\ ${ }^{1}$ Centre for Intelligent Healthcare, Faculty Health \& Life Sciences, Coventry University, UK \\ ${ }^{2}$ Yamaguchi University 1677-1 Yoshida, Yamaguchi, 753-8511, Japan
}

Received: 11 November, 2020

Accepted: 24 November, 2020

Published: 26 November, 2020

*Corresponding author: Ala Szczepura, Professor, Centre for Intelligent Healthcare, Faculty of Health \& Life Sciences, Coventry University, Richard Crossman Building, Priory Street, Coventry CV1 5FB, UK, Tel: +44 (0)7557 425 463; E-mail: ala.szczepura@coventry.ac.uk ORCID: https://orcid.org/0000-0001-6244-9872

Keywords: Robots; Robotics; Long-term care; Domiciliary care; Living lab; Smart home; Technology; Co-design; COVID-19; Big data

https://www.peertechz.com

\section{A Super-ageing population and challenges}

It is estimated that the world population aged $65+$ will triple from $6.9 \%$ to $20 \%$ by 2050 [1]. Across the world, different countries are at various stages in this super-ageing journey. Japan is the most rapidly ageing society with $28.2 \%$ now in this age group; in contrast, emerging economies such as India have some of the world's youngest populations $(6.1 \%$ aged $65+)$ [2]. The creation of super-aged societies will be without parallel in human history. While people may be living longer, it is also important to consider their Quality of Life (QoL), whether these additional years are 'healthy life years' [3]. Looking into the future, China is the country faced with the largest challenge in the next 30 years with a growth in older citizens to $26 \%$ of the population (366 million by 2050) [4]. An additional challenge associated with super-ageing is the group of increasingly frail older population (aged $85^{+}$) which is currently the fastest growing population world-wide; in the UK this is predicted to double in size by 2041 and treble by 2066 [5].

Policy makers consider that the challenges of a superageing population can partly be addressed through a policy of empowering senior citizens to continue living independently through use of assistive technology or 'ageing in place' [6]. But once frail older people need $24 / 7$ care, they need to move into some form of Long-Term Care (LTC) facility. These facilities need to be staffed, and a super-ageing society is inevitably faced with the additional challenge of fewer young people to enter this workforce. World-wide, the ratio of people aged 2064 years to those aged $65+$ is expected to halve by 2050 [1]. This problem can partly be addressed through informal carers. For older people wishing to continue to live independently at home, family members can act as unpaid informal carers, often while living some distance from their elderly relative and in paid employment. Currently, up to one quarter of older UK workers have caring responsibilities [7]. But in a LTC facility, even if assistive technologies are introduced, a committed and professionally trained workforce will still be required [8].

A major test for super-ageing societies will be whether care robots can be developed to help to address labour shortages both in domiciliary care and LTC facilities, and also to address professional skills shortages in LTC. The COVID-19 pandemic has triggered more rapid introduction of many new health technologies world-wide [9]. However, several important questions for any robotic solutions will be: are they commercially viable for the manufacturers and service provider, are they affordable for users, and can they maintain older people's QoL?

\section{Current technology landscape}

Various products currently exist to support older people in their own homes, although there is evidence of limited mass-market adoption by older adults living at home [10] and a poor fit between people's daily lives and the technologies produced $[11,12]$. One reason may be insufficient involvement of older people in the design of these technologies [13]. Also, for ambient monitoring technologies, family carers will need to respond to alerts and should be involved in co-design for effective operation [14]. As an example, technology to support informal carers of people with dementia is reported to still require significant development [15]. A very recent report, published in 2020 , also concludes that digital solutions alone have limited value, and use of robotic technology must now be considered to support caregivers [16].

From the LTC perspective, it has long been recognised that use of non-intrusive sensing technologies and social robots 
could improve organisational efficiency, quality of care and resident wellbeing [17]. Even so, use of such innovations is significantly under-developed in this sector, with cost, ease of use, and staff requirements identified as key barriers [18]. In addition, as ageing increases pressure on clinical staff, skillmix and training innovations are emerging in LTC world-wide. In Japan, there has been a move from medical and nursing staff as main providers of care to allowing care workers to undertake some clinical activities [19]. In the UK, because most LTC facilities have no on-site nursing, in-reach nursing models have been trialled [20] together with digital technology to enable medications to be administered by non-clinical staff [21]. In future, strategic investment in new technology, plus improved ways of professional working will be needed to address staff shortages and maintain the quality of care in LTC.

Remote sensors and safety devices, combined with Artificial Intelligence (AI), can be particularly useful for mobility recording and falls prevention/detection. Motion capture and wearable tracking technologies can provide older people with security while at home, and the freedom to move outside their home, especially if they have a condition such as dementia. Advances such as the 'Internet of Things' (IoT) and 'smart homes' can also provide information and alerts, relieving pressure on caregivers while supporting their caring work. Improved administrative systems, supported by AI and integrated care records, could help care staff to be more efficient, allowing more time for direct contact with older people and for care related tasks to be completed.

\section{A Living lab approach}

Although the evidence clearly demonstrates considerable potential for robot innovations to improve care, it appears that technology uptake has been limited to date. Historically, low rates of adoption have been linked to poor interface design, and issues of privacy and trust [22] as well as economic and training barriers [23]. One legacy of the COVID-19 pandemic is that healthcare providers worldwide have started to adopt new technology more rapidly, but the same effect is not evident in care homes [9]. Therefore, in order to address the challenges in the care sector, a new business model may be required in which companies can develop a series of new products (prototypes) for users to try, or see them in use, without committing to permanence following introduction. One model is the 'Living Lab' concept. Living labs are userfocused, experimental environments in which users and producers co-create innovative solutions in real-life settings. In 2017, a Data Driven Research and Innovation (DDRI) living lab programme was established in the UK for the superageing population. This involved a 24/7 living lab network, allowing multiple stakeholders to identify, test and refine new technology solutions, with technology transfer through an embedded innovation hub and national visitor programme [24]. Two registered systematic literature reviews are currently underway on the use of living labs in healthcare [25] and in the care of older people and individuals of all ages with learning disabilitie [26].

\section{The future robot care ecosystem}

In this section, we consider the future of robots in a superaged society. Typically, a personal robot assistant consists of sensors (input device), processing (intelligence \& control) and operations (output device) which enable it to undertake minor, repetitive care tasks [27]. Recent evaluations of commercial robots for this population point out challenges such as purchase cost; maintenance cost; difficulty in use; and safety concerns. However, it is interesting to see that LTC appears to be a 'forgotten sector' [28]. In a recent systematic review of research into how robotic technology can help older people, although 8,425 articles were identified among the studies finally included in the review none were undertaken in a LTC residential home and only one reported robot technology use in a nursing home [29]. Furthermore, a large-scale, nationallyfunded UK review which presented the evidence on innovation to enhance health in care homes (published a year later) failed to reference the first review and only included one study of robots in care homes (zoomorphic Paro) [18] This 'case example' demonstrates the need for trans-disciplinary, joined up working.

Older people will go through three stages as they age, (1) a time when they can live in good health and independence, (2) when they need some assistance in their daily life, while still being independent, and (3) when they eventually need fulltime support due to the complexity of their clinical and social care requirements. The ideal is to enable someone to live well, and in their own preferred way, during all three stages. Each stage has its own needs, and it is important to respond to these changing needs in order to develop the whole market. Robot use in stage (3) should also aim to improve the work environment of care staff as well as the lives of older people [8].

Standalone single task robots, or expert robots, provide special skills and support for activities such as: transfer and movement; toileting (excretion); watching over (observation); bathing; dressing; meals; oral care; medication; dementia/ cognitive therapies; functional training/physical activity; and communication. This form of robot will inevitably undergo incremental improvements in order to reach a commercially viable product with satisfied users, just like other consumer products e.g. cars, microwave ovens and washing machines.

However, more complex, multi-tasking autonomous robots such as nurse robots that involve communications, adaptions, decisions with sympathetic mind and common sense in some degree, will progress in a different manner. This is because these will be influenced by other rapidly and concurrently evolving technologies such as $5 \mathrm{G}$ telecommunications, IoT, sensors, natural language processing, AI and big data from care and health records. Safety and ethical dimensions are another difficult area here.

To date, companies appear not to have been able to fully grasp the needs and issues of the super-ageing population, but more recently, several consortia have been created for futureoriented innovation activities involving various companies from different business types, local residents, and governments

Citation: Szczepura A, Nomura T, Wild D (2020) The Future of Robots in a Super-Aged Society. Ann Robot Automation 4(1): 018-021. 
to learn from the actual conditions of older people and utilize them in product development [30]. The nature of innovation is changing from a technology push to discovery of values from society and customers, and to design activities. Thus, users will be an integral part of the innovation process. The Living Labs concept exemplified by the DDRI Programme at Coventry University and the Open Innovation 2.0 [31] are rightly placed in this context in comparison with the automotive and aviation industries (which are dominated by large companies). Open Innovation is reported to have a larger impact on an industry like robotics with many Small and Medium-sized Enterprises (SMEs), in terms of economic gains from patents, increased technology transfer and technology value [32].

Once care robots are connected to the outside world, we are then able to consider a wider picture of care services provision and applications infrastructure for a super-ageing society, including an integrated approach for LTC staff, doctors, nurses, pharmacists and family carers; and modeling, analytics, and prediction of individual user's health records, care facilities, transport planning, food delivery, etc. To this end, in 2020 the Science Council of Japan has established a national committee to address the challenge of an 'Aging Society with a Declining Birthrate' through forming the foundation of 'Care Science' to support the creation of a future [33].

Finally, although good design, user needs, and effectiveness are important, there are other factors that could influence final success, especially since many care robots are launched by SMEs with limited financial backing. Such factors include Government policy and the economy; interest rates, pricing and investment; product endorsement, and press coverage. We suggest that one approach to addressing these for domiciliary robots will be to run an international technology road-mapping workshop focusing on mid-term futures, say 15 years ahead. This may be the number of years before we have a satisfactory robot which can perform a reasonable number of tasks reliably.

\section{Conclusions and Future direction}

Care for older people in a super-aging society is a large, complex, and trans-disciplinary problem. Care assistive robots are indispensable as one of the key technologies for addressing the challenges faced by super-aging societies. However, robot manufacturers have yet to provide products that meet the needs and preferences of users, except for cases where the functions are clear. In terms of users, in many care facilities staff are insufficiently trained to handle care robots and this training need still has to be addressed. Also, manufacturers cannot be expected to keep investing large amounts of resources in fields where the market is unclear.

It is important in future to gradually improve and evaluate required functions, user preferences and design requirements through trans-disciplinary consortia of engineers, local governments, companies, care facilities staff and older people (including the frail older population). Such consortia will need to develop new business models to support an industry like 'care robotics' which involves many SMEs. To that end, new approaches for care innovation such as The Living Labs and Open Innovation 2.0 which have already begun to be implemented in Europe and the United States should be encouraged. Also, since future robots in other sectors will be connected to outside AI and big data, it is necessary to now start to build an ICT care platform that links physical space with cyberspace for health and medical care. In this context, a new framework of 'Care Science' is currently being advocated at the national level in Japan, without historical disciplinary barriers and fusing together organizations and specialties to meet the future challenges of a super-aged society. It will be interesting to see how other countries address this challenge.

\section{Author contributions}

The authors contributed equally to this manuscript but from different perspectives i.e. gerontological nursing (Prof Deidre Wild), systems and robotics (Prof Toshio Nomura) and health technology assessment (Prof Ala Szczepura).

\section{References}

1. OECD (2020) Population ageing: Facing the challenge. OECD Observer No 239 Link: https://bit.ly/2UV5IGI

2. Population Reference Bureau. Countries With the Oldest Populations in the World. 2020. Link: https://bit.ly/33a2KT2

3. Eurostat (2020) Healthy life years statistics (Data extracted in March 2020) European Commission. Link: https://bit.ly/2J32XAs

4. Population Reference Bureau (2020) Aging and Health in China: What Can We Learn From the World's Largest Population of Older People? Link: https://bit.ly/35VS1gG

5. Office for National Statistics (2018) Living longer: how our population is changing and why it matters. Overview of population ageing in the UK and some of the implications for the economy, public services, society and the individual. Office for National Statistics. Link: https://bit.ly/3ftncTx

6. National Institute on Aging (NIA) (2017) Aging in Place: Growing Older at Home. National Institutes of Health, USA. Link: https://bit.ly/3l10dk6

7. Office for National Statistics. Living longer: caring in later working life Examining the interplay between caring and working in later life in the UK. Office for National Statistics. Link: https://bit.ly/3714crO

8. Wild D, Szczepura A, Bowman C, Kydd ADW (2014) Differing perspectives on a role for technology in care homes to improve the lives of older people and the work environment of staff. Housing, Care and Support 17: 84-94. Link: https://bit.ly/360QCFq

9. Webster P (2020) Virtual health care in the era of COVID-19. Lancet 395: 11801181

10. Gutierrez FJ, Muñoz D, Ochoa SF, Tapia JM (2017) Assembling massmarket technology for the sake of wellbeing: A case study on the adoption of ambient intelligent systems by older adults living at home. Journal of Ambient Intelligence and Humanized Computing 1-21. Link: https://bit.ly/39a6BTL

11. Greenhalgh T, Procter R, Wherton J, Sugarhood P, Hinder S, et al. (2015) What is quality in assisted living technology? The ARCHIE framework for effective telehealth and telecare services. BMC Med 13: 91. Link: https://bit.ly/39b6mrB

12. Ward G, Fielden S, Muir H, Holliday N, Urwin G (2017) Developing the assistive technology consumer market for people aged $50-70$. Ageing and Society 37 : 1050-1067. Link: https://bit.ly/2J0g6db

13. Sumner J, Chong LS, Bundele A, Lim YW (2020) Co-Designing Technology for Aging in Place: A Systematic Review (Advance access publication June 7, 2020). Gerontologist. Link: https://bit.ly/3l1fLnZ

Citation: Szczepura A, Nomura T, Wild D (2020) The Future of Robots in a Super-Aged Society. Ann Robot Automation 4(1): 018-021. 
14. Carnemolla P (2018) Ageing in place and the internet of things - how smart home technologies, the built environment and caregiving intersect. Visualization in Engineering 6. Link: https://bit.ly/33a3Xd2

15. Lautenschlager NT, Diehl-Schmid J, Loi SM, Mayer J, Tensil M, et al. (2017) Modern technology to support carers of care recipients with dementia or functional mental illness: promising progress, but a long road ahead. Int Psychogeriatr 29: 1933-1935. Link: https://bit.ly/3I1XGG6

16. Thomas J (2020) A Review of Digital Technology Solutions to Support Caregivers. University of Strathclyde, acting through Digital Health \& Care Institute. Link: https://bit.ly/2UTIFwz

17. Szczepura A (2011) Residential and nursing homes: how can they meet the challenge of an aging population? Future Medicine - Aging Health 7: 877-887. Link: https://bit.ly/2J8ZdNj

18. Hanratty B, Craig D, Brittain K, Spilsbury K, Vines JPW (2019) Innovation to enhance health in care homes and evaluation of tools for measuring outcomes of care: rapid evidence synthesis. Health Serv Deliv Res 7. Link: https://bit.ly/2HvxNB3

19. Inoue T (2012) Developing the clinical abilities of care workers in Japan. Nurs Older People 24: 32-35. Link: https://bit.ly/3nVchVZ

20. Szczepura A, Nelson S, Wild D (2008) In-reach specialist nursing teams for residential care homes: uptake of services, impact on care provision and costeffectiveness. BMC Health Serv Res 8: 269. Link: https://bit.ly/3fryR5v

21. Szczepura A, Wild D, Nelson S (2011) Medication administration errors for older people in long-term residential care. BMC geriatrics 11: 82. Link: https://bit.ly/2JaTzKA

22. Yusif S, Soar J, Hafeez-Baig A (2016) Older people, assistive technologies, and the barriers to adoption: A systematic review. Int J Med Inform 94: 112-116. Link: https://bit.ly/2J909Bj

23. Wang J, Carroll D, Peck M, Myneni S, Gong Y (2016) Mobile and Wearable Technology Needs for Aging in Place: Perspectives from Older Adults and Their Caregivers and Providers. Stud Health Technol Inform 225: 486-490. Link: https://bit.ly/3frhMZv
24. Szczepura A, Collinson M, Moody L (2018) Living-Lab Concept: An Innovation Hub For Elderly Residential Care. . International Journal of Technology Assessment in Health Care 34: 99-100.

25. Archibald M, Lawless M, Woodgate R, Rieger K, Linton JSW (2020) A Systematic Review of Living Labs in Healthcare. PROSPERO 2020 CRD42020175275. Link: https://bit.ly/33tQYDd

26. Szczepura A, Nomura T, Wild D (2020) Technology introduction in care environments: systematic review of living lab models in diverse care settings. PROSPERO

27. Martinez-Martin E, del Pobil AP (2018) Personal robot assistants for elderly care: an overview. In: A Costa, V Julian, (Eds.) PN, eds. Personal Assistants: Emerging Computational Technologies Springer 77-91. Link: https://bit.ly/3m1MGKr

28. Nelson S, Wild D, Szczepura A (2009) The forgotten sector: the impact of change on workforce development in residential care for older people. Nursing and Residential Care 11: 200-204. Link: https://bit.ly/3nW8BTT

29. Shishehgar M, Kerr D, Blake J (2018) A systematic review of research into how robotic technology can help older people. Smart Health 7-8: 1-18. Link: https://bit.ly/2UX7w1u

30. SOMPO Holdings. Future Care Lab in Japan - A Theme Park for Security, Health \& Wellbeing. Link: https://bit.ly/2HAXz72

31. Curley MBS (2018) Open Innovation 2.0: The New Mode of Digital Innovation for Prosperity and Sustainability. Switzerland: Springer International Publishing. Link: https://bit.ly/2KABcjc

32. Yun JJ, Jeong ES, Lee YK, Kim KH (2018) The Effect of Open Innovation on Technology Value and Technology Transfer: A Comparative Analysis of the Automotive, Robotics, and Aviation Industries of Korea. Sustainability. Link: https://bit.ly/2KABPJA

33. Science Council of Japan, Clinical Medicine Committee / Health / Life Science Committee Joint Care Science Subcommittee in an Aging Society with a Declining Birthrate. Recommendation: Forming the foundation of care science and creating a future society (in Japanese). 2020
Discover a bigger Impact and Visibility of your article publication with Peertechz Publications

Copyright: (ㄷ 2020 Szczepura A, et al. This is an open-access article distributed under the terms of the Creative Commons Attribution License, which permits unrestricted use, distribution, and reproduction in any medium, provided the original author and source are credited.

Citation: Szczepura A, Nomura T, Wild D (2020) The Future of Robots in a Super-Aged Society. Ann Robot Automation 4(1): 018-021. 